OPEN ACCESS

Edited by:

Andrea Nistri,

Scuola Internazionale Superiore di

Studi Avanzati (SISSA), Italy

Reviewed by:

Miranda Mladinic,

University of Rijeka, Croatia

Silvia Corsini

Université Pierre et Marie Curie,

France

*Correspondence:

Shingo Kariya

sk2656@cumc.columbia.edu

Received: 10 January 2018

Accepted: 20 February 2018

Published: 06 March 2018

Citation:

Bucchia M, Merwin SJ, Re DB and

Kariya S (2018) Limitations

and Challenges in Modeling Diseases Involving Spinal Motor Neuron

Degeneration in Vitro.

Front. Cell. Neurosci. 12:61. doi: 10.3389/fncel.2018.00061

\section{Limitations and Challenges in Modeling Diseases Involving Spinal Motor Neuron Degeneration in Vitro}

\author{
Monica Bucchia', Samantha J. Merwin ${ }^{2}$, Diane B. $\operatorname{Re}^{2}$ and Shingo Kariya ${ }^{1 *}$ \\ ${ }^{1}$ Department of Neurology, Columbia University Medical Center, New York, NY, United States, ${ }^{2}$ Department of \\ Environmental Health Sciences, Columbia University Medical Center, New York, NY, United States
}

Pathogenic conditions involving degeneration of spinal motor neurons (MNs), such as amyotrophic lateral sclerosis, sarcopenia, and spinal cord injury, mostly occur in individuals whose spinal MNs are fully mature. There is currently no effective treatment to prevent death or promote axonal regeneration of the spinal MNs affected in these patients. To increase our understanding and find a cure for such conditions, easily controllable and monitorable cell culture models allow for a better dissection of certain molecular and cellular events that cannot be teased apart in whole organism models. To date, various types of spinal MN cultures have been described. Yet these models are all based on the use of immature neurons or neurons uncharacterized for their degree of maturity after being isolated and cultured. Additionally, studying only MNs cannot give a comprehensive and complete view of the neurodegenerative processes usually involving other cell types. To date, there is no confirmed in vitro model faithfully emulating disease or injury of the mature spinal MNs. In this review, we summarize the different limitations of currently available culture models, and discuss the challenges that have to be overcome for developing more reliable and translational platforms for the in vitro study of spinal $\mathrm{MN}$ degeneration.

Keywords: spinal motor neuron, neuromuscular junction, maturation, adult spinal cord, motor neuron culture, amyotrophic lateral sclerosis, sarcopenia, spinal cord injury

\section{LIMITATIONS}

\section{Immature vs. Mature}

Degeneration of matured spinal motor neurons (MNs) and their peripheral axons occurs in neurodegenerative disorders [e.g., amyotrophic lateral sclerosis (ALS)] (Kinsley and Siddique, 1993; Peters et al., 2015), as well as in aging (i.e., sarcopenia) (Aagaard et al., 2010; Berger and Doherty, 2010; Drey et al., 2014), and following spinal cord injury (Koliatsos et al., 1994; Li et al., 1995). There is currently no treatment that can effectively prevent death and promote axonal regeneration of the spinal MNs affected in these patients. To study such conditions, easily controllable and monitorable cell culture models allow for a better dissection of certain aspects of the disease mechanisms (e.g., direct live monitoring of cellular phenotypic changes or molecular cascades in response to stimuli) that are difficult to perform within a whole organism. In the past, many important progresses were made through in vitro studies utilizing primary spinal MNs isolated from mouse embryos or MNs differentiated from embryonic stem (ES) cells. However, 
these neurons are literally in their immature state (Arbab et al., 2014), raising the question of whether they are appropriate for modeling diseases that befall adults whose spinal MNs are fully matured. The groundbreaking discovery of the method for reprogramming differentiated cells into stem cells [induced pluripotent stem (iPS) cells] enabled us, for the first time, to unlimitedly expand and study MNs derived from adult patients (Takahashi and Yamanaka, 2006; Dimos et al., 2008; $\mathrm{Li}$ et al., 2008). While they obviously present significant advantages as a personalized and relatively non-invasive source of central nervous system (CNS)-relevant human material, a recent transcriptome study has revealed that iPS cell-derived MNs (iMNs) are closer to embryonic spinal MNs than to their freshly isolated adult counterparts (Ho et al., 2016). This finding brought a lot of disappointment to the field by highlighting that these adult-derived cells also share the same drawbacks as other currently available sources of MNs.

How do mouse spinal MNs differentiate and mature in vivo? At embryonic day (E) 9.5, gradient signals of two morphogens (retinoic acid and sonic hedgehog) created in the neural tube organize topographical positioning of neural precursor cells and induce their differentiation into spinal MNs (Pierani et al., 1999; Appel and Eisen, 2003; Novitch et al., 2003). These immature neurons start to express specific transcription factors, such as the homeobox gene HB9 and the LIM homeodomain genes Isl1 and $L h \times 3$, crucial for the spinal MNs to gain potential for projecting axons to peripheral muscles and releasing neurotransmitters (Wichterle et al., 2002; Rhee et al., 2016). After around E13, axonal terminals contacted to their muscle targets begin to form neuromuscular synapses [neuromuscular junctions (NMJs)], maturation of which is mostly completed by the end of the third postnatal week (Lichtman and Sanes, 2003; Kariya et al., 2008; Shi et al., 2012). During this period (E13-P21), the NMJ post-synapse, which is initially poly-innervated by multiple spinal MNs, becomes mono-innervated by a single spinal $\mathrm{MN}$ in the phenomenon known as axonal elimination (Culican et al., 1998; Keller-Peck et al., 2001; Walsh and Lichtman, 2003), and the NMJ pre-synapses that survived this competition gradually mature into a complex elaborated structure (Lichtman and Sanes, 2003; Shi et al., 2012). This process proceeds in morphological alignment with post-synaptic maturation from small and plaque-like to large pretzel shapes (Sanes and Lichtman, 2001; Lichtman and Sanes, 2003; Kariya et al., 2008; Shi et al., 2012). At NMJ pre-synapses, voltage-gated calcium channels are primarily $\mathrm{N}$ types (Cav2.2) in a neonatal stage (Rosato Siri and Uchitel, 1999; Santafé et al., 2001; Rosato-Siri et al., 2002; Urbano et al., 2003), but by P14 are eventually replaced and dominated with mature P/Q types (Cav2.1) (Uchitel et al., 1992; Bowersox et al., 1995; Katz et al., 1996; Rosato Siri and Uchitel, 1999; Nudler et al., 2003; Chand et al., 2015). Spinal MNs cannot engage in these maturation processes cell-autonomously, but through temporally regulated bidirectional interactions with muscle cells (Grinnell, 1995; Urbano et al., 2002; Lichtman and Sanes, 2003; Shi et al., 2012). Therefore, if simply plated as a sole pure population, cultured spinal MNs will never gain true maturity, even after long-term maintenance.

\section{Regenerating vs. Settled}

In vivo, peripheral axons of fully matured spinal MNs barely lengthen, but terminate at muscle fibers and form NMJs. The axonal terminals of these "settled" spinal MNs display highly specialized, large, and branched structures (NMJ pre-synapses) to efficiently and promptly execute their energy-consuming tasks, such as neurotransmitter release and vesicle recycling (Rash et al., 1988; Betz and Bewick, 1992; Morris and Hollenbeck, 1993; Hoopmann et al., 2012). In contrast, axonal terminals of immature spinal MNs grown in vitro manifest a hand-like morphology (growth cones) and are devoted to active regeneration, lengthening in response to neurotrophic factors supplemented in the culture media (Arakawa et al., 1990; Henderson et al., 1994; Estévez et al., 1998). These differences cannot be ignored, especially when the pathomechanisms of conditions attacking the settled spinal MNs in vivo are to be modeled and studied in vitro. Examples of such conditions include sarcopenia, characterized by an aging-associated pathological loss of muscle mass and strength (Aagaard et al., 2010; Berger and Doherty, 2010; Drey et al., 2014), and the adult-onset fatal neurodegenerative disorder ALS (Kinsley and Siddique, 1993). Mounting evidence indicates that sarcopenia involves the defective maintenance of mature NMJs and subsequent spinal MN death (Chai et al., 2011; Ławniczak and Kmieć, 2012; Tudoraşcu et al., 2014). While its exact etiology remains to be elucidated, sarcopenia clearly cannot simply be modeled by regenerating immature neurons in vitro. This concept would also apply for the in vitro modeling of ALS, whose central pathology primarily arises from degeneration of settled MNs (Cappello and Francolini, 2017). To correctly capture disease-relevant pathologies of these conditions in a dish, it may be most optimal from the translational point of view to first create mature NMJs before to start investigations.

The study of human conditions involving spinal $\mathrm{MN}$ degeneration can generally be broken down into three significant aspects: (i) the original cause or trigger of the disease (degeneration); (ii) the molecular and cellular cascade responsible for the degenerative process; and (iii) the regenerative mechanisms after the disease onset. An exception may be spinal cord injuries, for which (i) is already known. Studying the process of axonal regeneration in a simple $\mathrm{MN}$ mono-culture without muscle cells may sound reasonable, as this is a process prior to spinal $\mathrm{MN}$ settlement. However, careful attention still needs to be paid when utilizing embryonic neurons for understanding adult diseases, as their regenerative potential may not be the same as that of adult spinal MNs. The best would be to harvest primary spinal MNs from adult mice. In fact, several protocols detailing the methods for this are available (Milligan and Gifondorwa, 2011; Bektaš and Öztürk, 2013; Beaudet et al., 2015); however, they have thus far not being widely replicated. Additionally, the $\mathrm{MN}$ yields described in these studies are very low, encompassing the inherent risk of selecting the most resistant spinal $\mathrm{MN}$ populations and thus introducing a bias in their use for modeling diseases that in sharp contrast generally affect the most vulnerable populations of MNs. 


\section{Naked vs. Embedded}

In the ventral horn, spinal MNs are supported by glial cells at the structural, trophic, and metabolic levels (Blackburn et al., 2009; Christensen et al., 2013). Chondroitin sulfate proteoglycans secreted by astrocytes are the principal constituents of the extracellular matrix, known as perineuronal nets (Murakami and Ohtsuka, 2003; Haggerty et al., 2017), which not only serve as a scaffold for anchoring spinal MNs, but are also actively involved in neural signaling and plasticity (Maeda et al., 2010; Suttkus et al., 2016). Astrocytes also secrete multiple trophic factors regulating spinal MN survival and physiology, such as vascular endothelial growth factor (Van Damme, 2009) and glial cell-derived neurotrophic factor, which is also provided by neurons themselves and peripherally by Schwann cells and muscles via retrograde axonal transport (Springer et al., 1995; Houenou et al., 1996; Zahavi et al., 2015). Peripherally produced insulin-like growth factor- 1 crosses the blood-brain barrier and enhances the neuroprotective potential of astrocytes through binding to the receptors expressed on their cell membranes (Ang et al., 1993; Gray et al., 2017). Lactate released by astrocytes is believed to be taken up and utilized as an energy source by neurons (Béland-Millar et al., 2017). Other important functions of astrocytes include clearance of excess glutamate from the inter-synaptic space to prevent neuronal damage due to hyper-excitation (Barres, 1991). Microglia, another type of glial cells in the CNS, serve as the resident innate immune cells to protect CNS tissues from damaging events (e.g., infection, degeneration, and injury) (Loane and Byrnes, 2010; Amor et al., 2014). Finally, oligodendrocytes, the CNS counterpart of Schwann cells, insulate and nourish motor axons via the formation of myelin sheets (Jakovcevski et al., 2009; Saab and Nave, 2017). Spinal MNs "embedded" in the spinal cord in vivo receive all these glial benefits in a spatiotemporally regulated manner based on local biological requirements. This situation is quite different from that of dissociated or differentiated MNs harvested "naked" in a plate and forced to regenerate in culture media supplemented with fixed and spatially homogenous concentrations of trophic factors.

Despite the clearly biased environment of cultured spinal MNs in vitro, the naked neuron mono-culture is still useful for the investigation of certain biological aspects, such as the capture of disease-related cell-autonomous events. A high-throughput drug screening study that has recently been conducted by utilizing the survival of ALS patient iMNs as readout has identified bosutinib, the $\mathrm{Src} / \mathrm{c}-\mathrm{Abl}$ inhibitor approved by FDA for treating patients with chronic myelogenous leukemia, as a potential therapeutic candidate for ALS (Imamura et al., 2017). Another recent study has found, through deep transcriptome profiling, that maturation and aging-associated pathways are disrupted in sporadic ALS patient iMNs (Ho et al., 2016). In order to understand the pathogenic roles of astrocytes in ALS, we previously cultured control human ES MNs on monolayers of human primary cells obtained from ALS or non-ALS patients, and demonstrated the selective neurotoxic effect of astrocytes, but not fibroblasts, harvested from sporadic ALS patients (Re et al., 2014). Other groups have shown the neurotoxic effect of ALS microglia by using similar in vitro co-culture approaches (Liao et al., 2012; Frakes et al., 2014). Thus, co-culture with glial cells, if not a perfect modeling of the in vivo condition, can still help in identifying some disease-relevant mechanisms.

\section{SPINAL MOTOR NEURON SOURCE FOR CELL CULTURE}

Currently, there are two major spinal MN sources for in vitro studies: stem cell-derived MNs and embryonic mouse primary spinal MNs (Table 1). The most utilized stem cells for studying MN biology are mouse ES cells and human iPS cells. The main advantages of these cell lines compared to primary neurons are that they can unlimitedly be expanded and stored as homogeneous populations. They are thus suited for studies requiring a large quantity of neurons for repetitive tasks, such as drug screening, proteomics, and biochemistry. On the other hand, primary MNs, which have fully differentiated in vivo before being dissociated from the spinal cord, should possess a more genuine identity of spinal MNs compared with MNs differentiated in vitro from stem cells. In terms of purity and quantity, however, primary cultures often face variable contamination with other cell types, and the number of viable primary MNs obtainable per embryo is much more limited. Of prime importance, the iPS cells are the only source enabling us to study patient-derived $\mathrm{MNs}$ in vitro (Chipman et al., 2012). Several groups have succeeded to directly convert human fibroblasts into functional spinal MNs without transiting through a neural progenitor state (Son et al., 2011; Liu et al., 2013); however, improvement in the MN yield has to be achieved before this technique can be routinely utilized.

As an alternative to "naked" neuron cultures, primary spinal MNs can also be harvested as a form of organotypic spinal cord slices (Table 1). With this method, freshly dissected thin cross sections of the spinal cord are directly explanted in a dish. Thus, spinal MNs "embedded" in the explant do not undergo harsh procedures of chemical digestion and mechanical dissociation, but regenerate in vitro within a micro-environment resembling the in vivo condition. This culture system would also allow us to minimize the supplemental control of trophic factors as glial cells integrated in the system may supply them upon local requirements. Noteworthy, the freshly prepared spinal cord culture can serve as a ready-to-use platform for investigating neural networks by electrophysiological recording (Streit and Lüscher, 1992; Ulrich et al., 1994; Tscherter et al., 2001; Magloire and Streit, 2009). One disadvantage of the organotypic slice is that, even with the use of fluorescently labeled MNs, the dense axons freely outgrowing from the spinal MNs packed in the explant often make it difficult to perform a precise single neuron analysis. The motor axons need to be also distinguished from axons from other spinal neurons, such as interneurons (Avossa et al., 2003). Additionally, the intercellular relationships within the explant can eventually be disrupted during a long-term culture, losing the initial in vivo-like conditions. 
TABLE 1 | General features of currently available spinal motor neurons (MNs) for cell culture.

\begin{tabular}{|c|c|c|c|c|}
\hline & Stem cell-derived MN & Dissociated primary MN & Spinal cord explant & Mouse model \\
\hline MN purity & Good & Not perfect & $\begin{array}{l}\text { Presence of other cell types as } \\
\text { seen in vivo }\end{array}$ & N/A \\
\hline Application & $\begin{array}{l}\text { - Mechanisms in a single MN } \\
\text { - Screening }\end{array}$ & $\begin{array}{l}\text { - Mechanisms in a single MN } \\
\text { - Screening }\end{array}$ & $\begin{array}{l}\text { - Mechanisms in an integrated } \\
\text { system }\end{array}$ & $\begin{array}{l}\text { - Various in vivo studies } \\
\text { - Cells for in vitro studies }\end{array}$ \\
\hline Advantage & $\begin{array}{l}\text { - Expandable and storable } \\
\text { - Sortable } \\
\text { - Human iPS cell: } \\
\text { human-derived and } \\
\text { personalized }\end{array}$ & - Sortable & $\begin{array}{l}\text { - Retains micro-environment } \\
\text { of MNs in vivo } \\
\text { - Requires less supplemental } \\
\text { control }\end{array}$ & - Most translational \\
\hline \multirow[t]{3}{*}{ Disadvantage } & $\begin{array}{l}\text { - Could be less physiologic as } \\
\text { compared to primary MNs }\end{array}$ & $\begin{array}{l}\text { - Variable contamination of } \\
\text { other cell types }\end{array}$ & $\begin{array}{l}\text { - Not sortable } \\
\text { - Less quantifiable }\end{array}$ & $\begin{array}{l}\text { - Time consuming } \\
\text { - High cost for maintenance }\end{array}$ \\
\hline & \multicolumn{2}{|c|}{ Monitorable, controllable, and quantifiable } & & Complex \\
\hline & \multicolumn{2}{|l|}{ Artificial } & & Physiologic \\
\hline
\end{tabular}

\section{CHALLENGES}

\section{MN-Muscle Co-culture}

Knowing the significant applications that an in vitro model of mature NMJs could have, many investigators have attempted in the past to attain this objective (Braun et al., 1996, 1997; Daniels et al., 2000; Mars et al., 2001; Jevsek et al., 2004; Lanuza et al., 2006; Das et al., 2007; Guo et al., 2010, 2011; Lozano et al., 2016; Vilmont et al., 2016). In addition, the recently introduced technologies to differentiate stem cells into MNs have urged researchers to validate the potential of stem cell-derived MNs to form functional NMJs with muscle cells (Boza-Morán et al., 2015; Demestre et al., 2015; Toma et al., 2015; Yoshida et al., 2015; Steinbeck et al., 2016). What has emerged from these co-culture studies is that, regardless of the origin of MNs (i.e., primary or ES/iPS cell-derived), the extent to which NMJs can mature within a certain period of time is much less in a dish than inside the body. One crucial factor restricting the bona fide maturation of NMJs in the conventional MN-muscle cell co-culture is the biological limitation associated with the culture in a single medium or dish of different cell populations with different needs, precluding their healthy growth and maintenance. Considering that spinal MNs in vivo extend their axons into an environment different from that of their cell bodies, it is more reflective of the physiologic state to culture axons in a compartment distinct from their somas, but with muscle cells. For this reason, a growing number of studies employ a double-compartment micro-fluidic culture system, in which neurons plated in one compartment extend their axons through microgrooves into another compartment where muscle cells are growing (Campenot, 1977; Park et al., 2013; Southam et al., 2013; Zahavi et al., 2015; Uzel et al., 2016). By allowing manipulation of neurons and muscle cells separately in respective compartments, this system permits maximizing muscle cells to efficiently mature into large myofibers, the condition essential for the MN maturation (Sanes and Lichtman, 2001; Lichtman and Sanes, 2003; Shi et al., 2012). Another factor missing in the current models is the third key player for NMJ maturation: Schwann cells. These peripheral glial cells not only nourish MNs through formation of myelin sheaths along their motor axons, but also specialize into the one called terminal Schwann cell, which locally supports NMJ maturation and maintenance (Sanes and Lichtman, 1999; Feng et al., 2005; Sugiura and Lin, 2011; Darabid et al., 2014; Lee et al., 2017). Despite multiple studies demonstrating the beneficial effect of Schwann cells on neuroregeneration in conventional coculture systems (Ullian et al., 2004; Li et al., 2007; Gingras et al., 2008; Ragancokova et al., 2009; Gerardo-Nava et al., 2014; Hyung et al., 2015; Suh and Hyung, 2018), no study has thus far succeeded in incorporating Schwann cells into the in vitro model of NMJs: this difficulty can presumably be overcome by adopting a compartmented culture method as discussed above. While some progresses have been reported, the precise procedures (the timing for plating individual cell types, the culture medium formulation for each compartment at different time points, etc.) for establishing healthy mature and fully functional NMJs in compartmented systems are still under development.

\section{Adult Primary Spinal MN Culture}

What if we could achieve robust regeneration of adult mousederived mature spinal MNs in vitro? Difficulty in culturing these "grown-up" neurons is thought to be associated with their phenotypic changes. As animals grow, $\mathrm{MN}$ dendrites in the ventral horn become longer and form a more complex structure, which increases the chance of $\mathrm{MNs}$ to receive more injuries during the isolation, leading to their excitotoxicity-associated cell death (Lu et al., 2000; Momeni and Jarahzadeh, 2012; Rishal and Fainzilber, 2014). Another possibility is related to a decline in their intrinsic capacity for survival: unlike embryonic MNs, 
adult MNs are highly reliant on peripherally connected cells, such as Schwann cells and muscles, for their survival, making them terribly prone to death when trophic supports from these cells are suddenly shutdown after dissection (Lowrie and Vrbová, 1992; Oorschot and McLennan, 1998; Beck et al., 2001). As an approach to suppress such early death of MNs harvested in vitro, Bektaș and Öztürk (2013) have described the merit of pre-incubating plated MNs for a few days in a cold medium prior to induce axonal regeneration, while other study has shown the effectiveness of calcium channel blockers (Momeni and Jarahzadeh, 2012). Applying such findings to the organotypic adult spinal culture prepared in a compartmented system with muscle and Schwann cells in the periphery may give rise to more vivid $\mathrm{MN}$ regeneration. Overcoming this challenge would be extremely significant: (1) it will allow us to directly analyze various aspects of already-matured spinal MNs in vitro; (2) we will be able to compare and study, for the first time in vitro, spinal MNs from different stages of maturity (e.g., neonatal vs. adult vs. aged) or diseases (e.g., pre-symptomatic vs. postsymptomatic); and (3) it will serve as a novel cell source for drug screening. Yet, all these exciting applications are based on an assumption that adult spinal MNs plated in vitro continue to retain their "mature" properties previously acquired in vivo. Therefore, following successful isolation, it is important to verify whether these adult neurons remain as expected or retrieve "immature" properties during regeneration in an artificial in vitro environment.

\section{CONCLUSION}

Spinal MNs cannot truly mature and age alone. They need good supports and influences from multiple neighbors, or say "coworkers," like CNS glia and peripheral residents, such as Schwann cells and muscle cells. All these cells constituting the neuromuscular system benefit the MNs either directly

\section{REFERENCES}

Aagaard, P., Suetta, C., Caserotti, P., Magnusson, S. P., and Kjaer, M. (2010). Role of the nervous system in sarcopenia and muscle atrophy with aging: strength training as a countermeasure. Scand. J. Med. Sci. Sports 20, 49-64. doi: 10.1111/j.1600-0838.2009.01084.x

Amor, S., Peferoen, L. A., Vogel, D. Y. S., Breur, M., van der Valk, P., Baker, D., et al. (2014). Inflammation in neurodegenerative diseases-an update. Immunology 142, 151-166. doi: 10.1111/imm.12233

Ang, L. C., Bhaumick, B., and Juurlink, B. H. (1993). Neurite promoting activity of insulin, insulin-like growth factor I and nerve growth factor on spinal motoneurons is astrocyte dependent. Brain Res. Dev. Brain Res. 74, 83-88. doi: 10.1016/0165-3806(93)90086-P

Appel, B., and Eisen, J. S. (2003). Retinoids run rampant: multiple roles during spinal cord and motor neuron development. Neuron 40, 461-464. doi: 10.1016/ S0896-6273(03)00688-3

Arakawa, Y., Sendtner, M., and Thoenen, H. (1990). Survival effect of ciliary neurotrophic factor (CNTF) on chick embryonic motoneurons in culture: comparison with other neurotrophic factors and cytokines. J. Neurosci. 10, 3507-3515.

Arbab, M., Baars, S., and Geijsen, N. (2014). Modeling motor neuron disease: the matter of time. Trends Neurosci. 37, 642-652. doi: 10.1016/j.tins.2014. 07.008 or indirectly. Incidents or diseases sabotaging their good relationships may disrupt the healthy natural maturation and/or aging of spinal MNs, and often result in motor disorders of various severities. The different limitations that we have raised and discussed here apply not only to spinal MN cultures but also to in vitro models of many other cell types. Each culture model has different advantages and disadvantages; it is not a matter of which one is superior to the other. What is important is to select the one most fitted for individual objectives. The good news is that the range of possible models is widening, thanks to recent advance in technologies. Nonetheless, there is certainly still quite some room for progress, and further challenges have to be addressed toward establishing more reliable and translational in vitro platforms.

\section{AUTHOR CONTRIBUTIONS}

MB, SJM, DBR, and SK contributed to devising, editing, and revising of the manuscript.

\section{FUNDING}

This study was supported by an NIH/NIA R21AG052011 award to DBR and SK. MB was supported by the European Marie Curie 7PQ NO-MND staff exchange program grant.

\section{ACKNOWLEDGMENTS}

We thank Dr. Michio Hirano, the Merritt Clinical Research Center, Dr. Serge Przedborski, and the Motor Neuron Center. We sincerely apologize for not being able to mention and cite all of the excellent works that have contributed to this exciting field of research.

Avossa, D., Rosato-Siri, M. D., Mazzarol, F., and Ballerini, L. (2003). Spinal circuits formation: a study of developmentally regulated markers in organotypic cultures of embryonic mouse spinal cord. Neuroscience 122, 391-405. doi: 10.1016/j.neuroscience.2003.07.006

Barres, B. A. (1991). New roles for glia. J. Neurosci. 11, 3685-3694.

Beaudet, M.-J., Yang, Q., Cadau, S., Blais, M., Bellenfant, S., Gros-Louis, F., et al. (2015). High yield extraction of pure spinal motor neurons, astrocytes and microglia from single embryo and adult mouse spinal cord. Sci. Rep. 5:16763. doi: 10.1038/srep16763

Beck, M., Karch, C., Wiese, S., and Sendtner, M. (2001). Motoneuron cell death and neurotrophic factors: basic models for development of new therapeutic strategies in ALS. Amyotroph. Lateral Scler. Other Motor Neuron Disord. 2(Suppl. 1), S55-S68. doi: 10.1080/146608201750138585

Bektas̨, S., and Öztürk, G. (2013). Enhancement of cultured adult motor neuron survival with cold pre-incubation. Neurosci. Lett. 533, 23-27. doi: 10.1016/j. neulet.2012.11.013

Béland-Millar, A., Larcher, J., Courtemanche, J., Yuan, T., and Messier, C. (2017). Effects of systemic metabolic fuels on glucose and lactate levels in the brain extracellular compartment of the mouse. Front. Neurosci. 11:7. doi: 10.3389/ fnins.2017.00007

Berger, M. J., and Doherty, T. J. (2010). Sarcopenia: prevalence, mechanisms, and functional consequences. Interdiscip. Top. Gerontol. 37, 94-114. doi: 10.1159/ 000319997 
Betz, W. J., and Bewick, G. S. (1992). Optical analysis of synaptic vesicle recycling at the frog neuromuscular junction. Science 255, 200-203. doi: 10.1126/science. 1553547

Blackburn, D., Sargsyan, S., Monk, P. N., and Shaw, P. J. (2009). Astrocyte function and role in motor neuron disease: a future therapeutic target? Glia 57, 1251-1264. doi: 10.1002/glia.20848

Bowersox, S. S., Miljanich, G. P., Sugiura, Y., Li, C., Nadasdi, L., Hoffman, B. B., et al. (1995). Differential blockade of voltage-sensitive calcium channels at the mouse neuromuscular junction by novel omega-conopeptides and omegaagatoxin-IVA. J. Pharmacol. Exp. Ther. 273, 248-256.

Boza-Morán, M. G., Martínez-Hernández, R., Bernal, S., Wanisch, K., AlsoRallo, E., Le Heron, A., et al. (2015). Decay in survival motor neuron and plastin 3 levels during differentiation of iPSC-derived human motor neurons. Sci. Rep. 5:11696. doi: 10.1038/srep11696

Braun, S., Croizat, B., Lagrange, M. C., Poindron, P., and Warter, J. M. (1997). Degeneration of cocultures of spinal muscular atrophy muscle cells and rat spinal cord explants is not due to secreted factors and cannot be prevented by neurotrophins. Muscle Nerve 20, 953-960. doi: 10.1002/(SICI) 1097-4598(199708)20:8<953::AID-MUS4>3.0.CO;2-5

Braun, S., Croizat, B., Lagrange, M. C., Warter, J. M., and Poindron, P. (1996). Neurotrophins increase motoneurons' ability to innervate skeletal muscle fibers in rat spinal cord-human muscle cocultures. J. Neurol. Sci. 136, 17-23. doi: 10.1016/0022-510X(95)00315-S

Campenot, R. B. (1977). Local control of neurite development by nerve growth factor. Proc. Natl. Acad. Sci. U.S.A. 74, 4516-4519. doi: 10.1073/pnas.74.10.4516

Cappello, V., and Francolini, M. (2017). Neuromuscular junction dismantling in amyotrophic lateral sclerosis. Int. J. Mol. Sci. 18:E2092. doi: 10.3390/ ijms18102092

Chai, R. J., Vukovic, J., Dunlop, S., Grounds, M. D., and Shavlakadze, T. (2011). Striking denervation of neuromuscular junctions without lumbar motoneuron loss in geriatric mouse muscle. PLoS One 6:e28090. doi: 10.1371/journal.pone. 0028090

Chand, K. K., Lee, K. M., Schenning, M. P., Lavidis, N. A., and Noakes, P. G. (2015). Loss of $\beta 2$-laminin alters calcium sensitivity and voltage-gated calcium channel maturation of neurotransmission at the neuromuscular junction. J. Physiol. 593, 245-265. doi: 10.1113/jphysiol.2014.284133

Chipman, P. H., Toma, J. S., and Rafuse, V. F. (2012). Generation of motor neurons from pluripotent stem cells. Prog. Brain Res. 201, 313-331. doi: 10.1016/B9780-444-59544-7.00015-9

Christensen, R. K., Petersen, A. V., and Perrier, J.-F. (2013). How do glial cells contribute to motor control? Curr. Pharm. Des. 19, 4385-4399.

Culican, S. M., Nelson, C. C., and Lichtman, J. W. (1998). Axon withdrawal during synapse elimination at the neuromuscular junction is accompanied by disassembly of the postsynaptic specialization and withdrawal of Schwann cell processes. J. Neurosci. 18, 4953-4965.

Daniels, M. P., Lowe, B. T., Shah, S., Ma, J., Samuelsson, S. J., Lugo, B., et al. (2000). Rodent nerve-muscle cell culture system for studies of neuromuscular junction development: refinements and applications. Microsc. Res. Tech. 49, 26-37. doi: 10.1002/(SICI)1097-0029(20000401)49:1<26::AID-JEMT4<3.0.CO;2-8

Darabid, H., Perez-Gonzalez, A. P., and Robitaille, R. (2014). Neuromuscular synaptogenesis: coordinating partners with multiple functions. Nat. Rev. Neurosci. 15, 703-718. doi: 10.1038/nrn3821

Das, M., Rumsey, J. W., Gregory, C. A., Bhargava, N., Kang, J.-F., Molnar, P., et al. (2007). Embryonic motoneuron-skeletal muscle co-culture in a defined system. Neuroscience 146, 481-488. doi: 10.1016/j.neuroscience.2007.01.068

Demestre, M., Orth, M., Föhr, K. J., Achberger, K., Ludolph, A. C., Liebau, S., et al. (2015). Formation and characterisation of neuromuscular junctions between hiPSC derived motoneurons and myotubes. Stem Cell Res. 15, 328-336. doi: 10.1016/j.scr.2015.07.005

Dimos, J. T., Rodolfa, K. T., Niakan, K. K., Weisenthal, L. M., Mitsumoto, H., Chung, W., et al. (2008). Induced pluripotent stem cells generated from patients with ALS can be differentiated into motor neurons. Science 321, 1218-1221. doi: 10.1126/science. 1158799

Drey, M., Krieger, B., Sieber, C. C., Bauer, J. M., Hettwer, S., Bertsch, T., et al. (2014). Motoneuron loss is associated with sarcopenia. J. Am. Med. Dir. Assoc. 15, 435-439. doi: 10.1016/j.jamda.2014.02.002

Estévez, A. G., Spear, N., Thompson, J. A., Cornwell, T. L., Radi, R., Barbeito, L., et al. (1998). Nitric oxide-dependent production of cGMP supports the survival of rat embryonic motor neurons cultured with brain-derived neurotrophic factor. J. Neurosci. 18, 3708-3714.

Feng, Z., Koirala, S., and Ko, C.-P. (2005). Synapse-glia interactions at the vertebrate neuromuscular junction. Neuroscientist 11, 503-513. doi: 10.1177/ 1073858405277409

Frakes, A. E., Ferraiuolo, L., Haidet-Phillips, A. M., Schmelzer, L., Braun, L., Miranda, C. J., et al. (2014). Microglia induce motor neuron death via the classical NF- $\mathrm{B}$ pathway in amyotrophic lateral sclerosis. Neuron 81, 1009-1023. doi: 10.1016/j.neuron.2014.01.013

Gerardo-Nava, J., Hodde, D., Katona, I., Bozkurt, A., Grehl, T., Steinbusch, H. W., et al. (2014). Spinal cord organotypic slice cultures for the study of regenerating motor axon interactions with 3D scaffolds. Biomaterials 35, 4288-4296. doi: 10.1016/j.biomaterials.2014.02.007

Gingras, M., Beaulieu, M. M., Gagnon, V., Durham, H. D., and Berthod, F. (2008). In vitro study of axonal migration and myelination of motor neurons in a three-dimensional tissue-engineered model. Glia 56, 354-364. doi: 10.1002/glia. 20617

Gray, S. M., Aylor, K. W., and Barrett, E. J. (2017). Unravelling the regulation of insulin transport across the brain endothelial cell. Diabetologia 60, 1512-1521. doi: 10.1007/s00125-017-4285-4

Grinnell, A. D. (1995). Dynamics of nerve-muscle interaction in developing and mature neuromuscular junctions. Physiol. Rev. 75, 789-834. doi: 10.1152/ physrev.1995.75.4.789

Guo, X., Das, M., Rumsey, J., Gonzalez, M., Stancescu, M., and Hickman, J. (2010). Neuromuscular junction formation between human stem-cell-derived motoneurons and rat skeletal muscle in a defined system. Tissue Eng. Part C Methods 16, 1347-1355. doi: 10.1089/ten.tec.2010.0040

Guo, X., Gonzalez, M., Stancescu, M., Vandenburgh, H. H., and Hickman, J. J. (2011). Neuromuscular junction formation between human stem cell-derived motoneurons and human skeletal muscle in a defined system. Biomaterials 32, 9602-9611. doi: 10.1016/j.biomaterials.2011.09.014

Haggerty, A. E., Marlow, M. M., and Oudega, M. (2017). Extracellular matrix components as therapeutics for spinal cord injury. Neurosci. Lett. 652, 50-55. doi: 10.1016/j.neulet.2016.09.053

Henderson, C. E., Phillips, H. S., Pollock, R. A., Davies, A. M., Lemeulle, C., Armanini, M., et al. (1994). GDNF: a potent survival factor for motoneurons present in peripheral nerve and muscle. Science 266, 1062-1064. doi: 10.1126/ science.7973664

Ho, R., Sances, S., Gowing, G., Amoroso, M. W., O’Rourke, J. G., Sahabian, A., et al. (2016). ALS disrupts spinal motor neuron maturation and aging pathways within gene co-expression networks. Nat. Neurosci. 19, 1256-1267. doi: 10.1038/nn.4345

Hoopmann, P., Rizzoli, S. O., and Betz, W. J. (2012). Imaging synaptic vesicle recycling by staining and destaining vesicles with FM dyes. Cold Spring Harb. Protoc. 2012, 77-83. doi: 10.1101/pdb.prot067603

Houenou, L. J., Oppenheim, R. W., Li, L., Lo, A. C., and Prevette, D. (1996). Regulation of spinal motoneuron survival by GDNF during development and following injury. Cell Tissue Res. 286, 219-223. doi: 10.1007/s004410050690

Hyung, S., Yoon Lee, B., Park, J. C., Kim, J., Hur, E. M., and Francis Suh, J. K. (2015). Coculture of primary motor neurons and schwann cells as a model for in vitro myelination. Sci. Rep. 5:15122. doi: 10.1038/srep15122

Imamura, K., Izumi, Y., Watanabe, A., Tsukita, K., Woltjen, K., Yamamoto, T., et al. (2017). The Src/c-Abl pathway is a potential therapeutic target in amyotrophic lateral sclerosis. Sci. Transl. Med. 9:eaaf3962. doi: 10.1126/scitranslmed.aaf3962

Jakovcevski, I., Filipovic, R., Mo, Z., Rakic, S., and Zecevic, N. (2009). Oligodendrocyte development and the onset of myelination in the human fetal brain. Front. Neuroanat. 3:5. doi: 10.3389/neuro.05.005.2009

Jevsek, M., Mars, T., Mis, K., and Grubic, Z. (2004). Origin of acetylcholinesterase in the neuromuscular junction formed in the in vitro innervated human muscle. Eur. J. Neurosci. 20, 2865-2871. doi: 10.1111/j.1460-9568.2004.03752.x

Kariya, S., Park, G.-H., Maeno-Hikichi, Y., Leykekhman, O., Lutz, C., Arkovitz, M. S., et al. (2008). Reduced SMN protein impairs maturation of the neuromuscular junctions in mouse models of spinal muscular atrophy. Hum. Mol. Genet. 17, 2552-2569. doi: 10.1093/hmg/ddn156

Katz, E., Ferro, P. A., Weisz, G., and Uchitel, O. D. (1996). Calcium channels involved in synaptic transmission at the mature and regenerating mouse neuromuscular junction. J. Physiol. 497(Pt 3), 687-697. doi: 10.1113/jphysiol. 1996.sp021800 
Keller-Peck, C. R., Walsh, M. K., Gan, W. B., Feng, G., Sanes, J. R., and Lichtman, J. W. (2001). Asynchronous synapse elimination in neonatal motor units: studies using GFP transgenic mice. Neuron 31, 381-394. doi: 10.1016/S08966273(01)00383-X

Kinsley, L., and Siddique, T. (1993). “Amyotrophic lateral sclerosis overview," in SourceGeneReviews ${ }^{\circledR}$, eds M. P. Adam, H. H. Ardinger, R. A. Pagon, S. E. Wallace, L. J. H. Bean, K. Stephens, et al. (Seattle, WA: University of Washington), 1993-2018.

Koliatsos, V. E., Price, W. L., Pardo, C. A., and Price, D. L. (1994). Ventral root avulsion: an experimental model of death of adult motor neurons. J. Comp. Neurol. 342, 35-44. doi: 10.1002/cne.903420105

Lanuza, M. A., Gizaw, R., Viloria, A., González, C. M., Besalduch, N., Dunlap, V., et al. (2006). Phosphorylation of the nicotinic acetylcholine receptor in myotube-cholinergic neuron cocultures. J. Neurosci. Res. 83, 1407-1414. doi: 10.1002/jnr.20848

Ławniczak, A., and Kmieć, Z. (2012). Age-related changes of skeletal muscles: physiology, pathology and regeneration. Postepy Hig. Med. Dosw. 66, 392-400. doi: 10.5604/17322693.1000902

Lee, Y., Thompson, W. J., and Harlow, M. L. (2017). Schwann cells participate in synapse elimination at the developing neuromuscular junction. Curr. Opin. Neurobiol. 47, 176-181. doi: 10.1016/j.conb.2017.10.010

Li, J., Sun, C. R., Zhang, H., Tsang, K. S., Li, J. H., Zhang, S. D., et al. (2007). Induction of functional recovery by co-transplantation of neural stem cells and Schwann cells in a rat spinal cord contusion injury model. Biomed. Environ. Sci. 20, 242-249.

Li, L., Wu, W., Lin, L. F., Lei, M., Oppenheim, R. W., and Houenou, L. J. (1995). Rescue of adult mouse motoneurons from injury-induced cell death by glial cell line-derived neurotrophic factor. Proc. Natl. Acad. Sci. U.S.A. 92, 9771-9775. doi: 10.1073/pnas.92.21.9771

Li, X.-J., Hu, B.-Y., Jones, S. A., Zhang, Y.-S., Lavaute, T., Du, Z.-W., et al. (2008). Directed differentiation of ventral spinal progenitors and motor neurons from human embryonic stem cells by small molecules. Stem Cells 26, 886-893. doi: 10.1634/stemcells.2007-0620

Liao, B., Zhao, W., Beers, D. R., Henkel, J. S., and Appel, S. H. (2012). Transformation from a neuroprotective to a neurotoxic microglial phenotype in a mouse model of ALS. Exp. Neurol. 237, 147-152. doi: 10.1016/j.expneurol. 2012.06.011

Lichtman, J. W., and Sanes, J. R. (2003). Watching the neuromuscular junction. J. Neurocytol. 32, 767-775. doi: 10.1023/B:NEUR.0000020622.58471.37

Liu, M.-L., Zang, T., Zou, Y., Chang, J. C., Gibson, J. R., Huber, K. M., et al. (2013). Small molecules enable neurogenin 2 to efficiently convert human fibroblasts into cholinergic neurons. Nat. Commun. 4:2183. doi: 10.1038/ncomms3183

Loane, D. J., and Byrnes, K. R. (2010). Role of microglia in neurotrauma. Neurotherapeutics 7, 366-377. doi: 10.1016/j.nurt.2010.07.002

Lowrie, M. B., and Vrbová, G. (1992). Dependence of postnatal motoneurones on their targets: review and hypothesis. Trends Neurosci. 15, 80-84. doi: 10.1016/ 0166-2236(92)90014-Y

Lozano, R., Gilmore, K. J., Thompson, B. C., Stewart, E. M., Waters, A. M., RomeroOrtega, M., et al. (2016). Electrical stimulation enhances the acetylcholine receptors available for neuromuscular junction formation. Acta Biomater. 45 328-339. doi: 10.1016/j.actbio.2016.08.006

Lu, J., Ashwell, K. W., and Waite, P. (2000). Advances in secondary spinal cord injury: role of apoptosis. Spine 25, 1859-1866. doi: 10.1097/00007632200007150-00022

Maeda, N., Fukazawa, N., and Ishii, M. (2010). Chondroitin sulfate proteoglycans in neural development and plasticity. Front. Biosci. 15, 626-644. doi: 10.2741/ 3637

Magloire, V., and Streit, J. (2009). Intrinsic activity and positive feedback in motor circuits in organotypic spinal cord slice cultures. Eur. J. Neurosci. 30, 1487-1497. doi: 10.1111/j.1460-9568.2009.06978.x

Mars, T., Yu, K. J., Tang, X. M., Miranda, A. F., Grubic, Z., Cambi, F., et al. (2001). Differentiation of glial cells and motor neurons during the formation of neuromuscular junctions in cocultures of rat spinal cord explant and human muscle. J. Comp. Neurol. 438, 239-251. doi: 10.1002/cne. 1312

Milligan, C., and Gifondorwa, D. (2011). Isolation and culture of postnatal spinal motoneurons. Methods Mol. Biol. 793, 77-85. doi: 10.1007/978-1-61779328-8_5
Momeni, H. R., and Jarahzadeh, M. (2012). Effects of a voltage sensitive calcium channel blocker and a sodium-calcium exchanger inhibitor on apoptosis of motor neurons in adult spinal cord slices. Cell J. 14, 171-176.

Morris, R. L., and Hollenbeck, P. J. (1993). The regulation of bidirectional mitochondrial transport is coordinated with axonal outgrowth. J. Cell Sci. 104(Pt 3), 917-927.

Murakami, T., and Ohtsuka, A. (2003). Perisynaptic barrier of proteoglycans in the mature brain and spinal cord. Arch. Histol. Cytol. 66, 195-207. doi: 10.1679/ aohc.66.195

Novitch, B. G., Wichterle, H., Jessell, T. M., and Sockanathan, S. (2003). A requirement for retinoic acid-mediated transcriptional activation in ventral neural patterning and motor neuron specification. Neuron 40, 81-95. doi: 10 . 1016/j.neuron.2003.08.006

Nudler, S., Piriz, J., Urbano, F. J., Rosato-Siri, M. D., Renteria, E. S. P., and Uchitel, O. D. (2003). $\mathrm{Ca}^{2+}$ channels and synaptic transmission at the adult, neonatal, and P/Q-type deficient neuromuscular junction. Ann. N. Y. Acad. Sci. 998, 11-17. doi: 10.1196/annals. 1254.003

Oorschot, D. E., and McLennan, I. S. (1998). The trophic requirements of mature motoneurons. Brain Res. 789, 315-321. doi: 10.1016/S0006-8993(98)00028-6

Park, H. S., Liu, S., McDonald, J., Thakor, N., and Yang, I. H. (2013). Neuromuscular junction in a microfluidic device. Conf. IEEE Eng. Med. Biol. Soc. 2013, 2833-2835. doi: 10.1109/EMBC.2013.6610130

Peters, O. M., Ghasemi, M., and Brown, R. H. (2015). Emerging mechanisms of molecular pathology in ALS. J. Clin. Invest. 125, 1767-1779. doi: 10.1172/ JCI71601

Pierani, A., Brenner-Morton, S., Chiang, C., and Jessell, T. M. (1999). A sonic hedgehog-independent, retinoid-activated pathway of neurogenesis in the ventral spinal cord. Cell 97, 903-915. doi: 10.1016/S0092-8674(00)80802-8

Ragancokova, D., Jahn, K., Kotsiari, A., Schlesinger, F., Haastert, K., Stangel, M., et al. (2009). Analysis of neuroprotective effects of valproic acid on primary motor neurons in monoculture or co-cultures with astrocytes or Schwann cells. Cell. Mol. Neurosci. 29, 1037-1043. doi: 10.1007/s10571-009-9393-3

Rash, J. E., Walrond, J. P., Morita, M., and McCracken, T. O. (1988). Structural and functional correlates of synaptic transmission in the vertebrate neuromuscular junction. J. Electron Microsc. Tech. 10, 153-185. doi: 10.1002/jemt.1060100204

Re, D. B., Le Verche, V., Yu, C., Amoroso, M. W., Politi, K. A., Phani, S., et al. (2014). Necroptosis drives motor neuron death in models of both sporadic and familial ALS. Neuron 81, 1001-1008. doi: 10.1016/j.neuron.2014. 01.011

Rhee, H. S., Closser, M., Guo, Y., Bashkirova, E. V., Tan, G. C., Gifford, D. K., et al. (2016). Expression of terminal effector genes in mammalian neurons is maintained by a dynamic relay of transient enhancers. Neuron 92, 1252-1265. doi: 10.1016/j.neuron.2016.11.037

Rishal, I., and Fainzilber, M. (2014). Axon-soma communication in neuronal injury. Nat. Rev. Neurosci. 15, 32-42. doi: 10.1038/nrn3609

Rosato Siri, M. D., and Uchitel, O. D. (1999). Calcium channels coupled to neurotransmitter release at neonatal rat neuromuscular junctions. J. Physiol. 514(Pt 2), 533-540. doi: 10.1111/j.1469-7793.1999.533ae.x

Rosato-Siri, M. D., Piriz, J., Tropper, B. A., and Uchitel, O. D. (2002). Differential $\mathrm{Ca}^{2+}$-dependence of transmitter release mediated by P/Q- and N-type calcium channels at neonatal rat neuromuscular junctions. Eur. J. Neurosci. 15, 1874-1880. doi: 10.1046/j.1460-9568.2002.02015.x

Saab, A. S., and Nave, K.-A. (2017). Myelin dynamics: protecting and shaping neuronal functions. Curr. Opin. Neurobiol. 47, 104-112. doi: 10.1016/j.conb. 2017.09.013

Sanes, J. R., and Lichtman, J. W. (1999). Development of the vertebrate neuromuscular junction. Annu. Rev. Neurosci. 22, 389-442. doi: 10.1146/ annurev.neuro.22.1.389

Sanes, J. R., and Lichtman, J. W. (2001). Induction, assembly, maturation and maintenance of a postsynaptic apparatus. Nat. Rev. Neurosci. 2, 791-805. doi: $10.1038 / 35097557$

Santafé, M. M., Garcia, N., Lanuza, M. A., Uchitel, O. D., and Tomás, J. (2001). Calcium channels coupled to neurotransmitter release at dually innervated neuromuscular junctions in the newborn rat. Neuroscience 102, 697-708. doi: 10.1016/S0306-4522(00)00507-8

Shi, L., Fu, A. K., and Ip, N. Y. (2012). Molecular mechanisms underlying maturation and maintenance of the vertebrate neuromuscular junction. Trends Neurosci. 35, 441-453. doi: 10.1016/j.tins.2012.04.005 
Son, E. Y., Ichida, J. K., Wainger, B. J., Toma, J. S., Rafuse, V. F., Woolf, C. J., et al. (2011). Conversion of mouse and human fibroblasts into functional spinal motor neurons. Cell Stem Cell 9, 205-218. doi: 10.1016/j.stem.2011.07.014

Southam, K. A., King, A. E., Blizzard, C. A., McCormack, G. H., and Dickson, T. C. (2013). Microfluidic primary culture model of the lower motor neuron-neuromuscular junction circuit. J. Neurosci. Methods 218, 164-169. doi: 10.1016/j.jneumeth.2013.06.002

Springer, J. E., Seeburger, J. L., He, J., Gabrea, A., Blankenhorn, E. P., and Bergman, L. W. (1995). cDNA sequence and differential mRNA regulation of two forms of glial cell line-derived neurotrophic factor in Schwann cells and rat skeletal muscle. Exp. Neurol. 131, 47-52. doi: 10.1016/0014-4886(95)90006-3

Steinbeck, J. A., Jaiswal, M. K., Calder, E. L., Kishinevsky, S., Weishaupt, A., Toyka, K. V., et al. (2016). Functional connectivity under optogenetic control allows modeling of human neuromuscular disease. Cell Stem Cell 18, 134-143. doi: $10.1016 /$ j.stem.2015.10.002

Streit, J., and Lüscher, H. R. (1992). Miniature excitatory postsynaptic potentials in embryonic motoneurons grown in slice cultures of spinal cord, dorsal root ganglia and skeletal muscle. Exp. Brain Res. 89, 453-458. doi: 10.1007/ BF00228262

Sugiura, Y., and Lin, W. (2011). Neuron-glia interactions: the roles of Schwann cells in neuromuscular synapse formation and function. Biosci. Rep. 31, 295-302. doi: 10.1042/BSR20100107

Suh, J. F., and Hyung, S. (2018). Primary motor neuron culture to promote cellular viability and myelination. Methods Mol. Biol. 1727, 403-411. doi: 10.1007/9781-4939-7571-6_32

Suttkus, A., Morawski, M., and Arendt, T. (2016). Protective properties of neural extracellular matrix. Mol. Neurobiol. 53, 73-82. doi: 10.1007/s12035-0148990-4

Takahashi, K., and Yamanaka, S. (2006). Induction of pluripotent stem cells from mouse embryonic and adult fibroblast cultures by defined factors. Cell 126, 663-676. doi: 10.1016/j.cell.2006.07.024

Toma, J. S., Shettar, B. C., Chipman, P. H., Pinto, D. M., Borowska, J. P., Ichida, J. K., et al. (2015). Motoneurons derived from induced pluripotent stem cells develop mature phenotypes typical of endogenous spinal motoneurons. J. Neurosci. 35, 1291-1306. doi: 10.1523/JNEUROSCI.2126-14.2015

Tscherter, A., Heuschkel, M. O., Renaud, P., and Streit, J. (2001). Spatiotemporal characterization of rhythmic activity in rat spinal cord slice cultures. Eur. J. Neurosci. 14, 179-190. doi: 10.1046/j.0953-816x.2001.01635.x

Tudoraşcu, I., Sfredel, V., Riza, A. L., Dănciulescu Miulescu, R., Ianoşi, S. L., and Dănoiu, S. (2014). Motor unit changes in normal aging: a brief review. Rom. J. Morphol. Embryol. 55, 1295-1301.

Uchitel, O. D., Protti, D. A., Sanchez, V., Cherksey, B. D., Sugimori, M., and Llinás, R. (1992). P-type voltage-dependent calcium channel mediates presynaptic calcium influx and transmitter release in mammalian synapses. Proc. Natl. Acad. Sci. U.S.A. 89, 3330-3333. doi: 10.1073/pnas.89.8.3330

Ullian, E. M., Harris, B. T., Wu, A., Chan, J. R., and Barres, B. A. (2004). Schwann cells and astrocytes induce synapse formation by spinal motor neurons in culture. Mol. Cell. Neurosci. 25, 241-251. doi: 10.1016/j.mcn.2003.10.011
Ulrich, D., Quadroni, R., and Lüscher, H. R. (1994). Electronic structure of motoneurons in spinal cord slice cultures: a comparison of compartmental and equivalent cylinder models. J. Neurophysiol. 72, 861-871. doi: 10.1152/jn.1994. 72.2 .861

Urbano, F. J., Piedras-Rentería, E. S., Jun, K., Shin, H.-S., Uchitel, O. D., and Tsien, R. W. (2003). Altered properties of quantal neurotransmitter release at endplates of mice lacking P/Q-type $\mathrm{Ca}^{2+}$ channels. Proc. Natl. Acad. Sci. U.S.A. 100, 3491-3496. doi: 10.1073/pnas.0437991100

Urbano, F. J., Rosato-Siri, M. D., and Uchitel, O. D. (2002). Calcium channels involved in neurotransmitter release at adult, neonatal and P/Q-type deficient neuromuscular junctions (Review). Mol. Membr. Biol. 19, 293-300. doi: 10.1080/0968768021000035087

Uzel, S. G. M., Platt, R. J., Subramanian, V., Pearl, T. M., Rowlands, C. J., Chan, V., et al. (2016). Microfluidic device for the formation of optically excitable, three-dimensional, compartmentalized motor units. Sci. Adv. 2:e1501429. doi: $10.1126 /$ sciadv.1501429

Van Damme, P. (2009). The role of AMPA receptors and VEGF in ALS. Verh. K. Acad. Geneeskd. Belg. 71, 241-250.

Vilmont, V., Cadot, B., Ouanounou, G., and Gomes, E. R. (2016). A system for studying mechanisms of neuromuscular junction development and maintenance. Development 143, 2464-2477. doi: 10.1242/dev.13 0278

Walsh, M. K., and Lichtman, J. W. (2003). In vivo time-lapse imaging of synaptic takeover associated with naturally occurring synapse elimination. Neuron 37 , 67-73. doi: 10.1016/S0896-6273(02)01142-X

Wichterle, H., Lieberam, I., Porter, J. A., and Jessell, T. M. (2002). Directed differentiation of embryonic stem cells into motor neurons. Cell 110, 385-397. doi: 10.1016/S0092-8674(02)00835-8

Yoshida, M., Kitaoka, S., Egawa, N., Yamane, M., Ikeda, R., Tsukita, K., et al. (2015). Modeling the early phenotype at the neuromuscular junction of spinal muscular atrophy using patient-derived iPSCs. Stem Cell Rep. 4, 561-568. doi: 10.1016/j.stemcr.2015.02.010

Zahavi, E. E., Ionescu, A., Gluska, S., Gradus, T., Ben-Yaakov, K., and Perlson, E. (2015). A compartmentalized microfluidic neuromuscular co-culture system reveals spatial aspects of GDNF functions. J. Cell Sci. 128, 1241-1252. doi: $10.1242 /$ jcs. 167544

Conflict of Interest Statement: The authors declare that the research was conducted in the absence of any commercial or financial relationships that could be construed as a potential conflict of interest.

Copyright (C) 2018 Bucchia, Merwin, Re and Kariya. This is an open-access article distributed under the terms of the Creative Commons Attribution License (CC BY). The use, distribution or reproduction in other forums is permitted, provided the original author(s) and the copyright owner are credited and that the original publication in this journal is cited, in accordance with accepted academic practice. No use, distribution or reproduction is permitted which does not comply with these terms. 